\title{
pH-control of the protein resistance of thin hydrogel gradient films
}

\author{
Feng-i Tai, Olof Sterner, Olof Andersson, Tobias Ekblad and Thomas Ederth
}

\section{Linköping University Post Print}

\section{Tweet}

N.B.: When citing this work, cite the original article.

Original Publication:

Feng-i Tai, Olof Sterner, Olof Andersson, Tobias Ekblad and Thomas Ederth, pH-control of the protein resistance of thin hydrogel gradient films, 2014, Soft Matter, (10), 32, 5955-5964. http://dx.doi.org/10.1039/c4sm00833b

Copyright: Royal Society of Chemistry http://www.rsc.org/

Postprint available at: Linköping University Electronic Press

http://urn.kb.se/resolve?urn=urn:nbn:se:liu:diva-110502 


\title{
$\mathrm{pH}$-control of the protein resistance of thin hydrogel gradient films
}

\author{
Feng-I Tai, Olof Sterner ${ }^{1}$, Olof Andersson ${ }^{2}$, Tobias Ekblad ${ }^{3}$ and Thomas Ederth* \\ Division of Molecular Physics, Department of Physics, Chemistry and Biology, Linköping \\ University, SE-581 83 Linköping, Sweden
}

${ }^{1}$ Present address: ETH Zürich, Laboratory for Surface Science and Technology, Wolfgang-Pauli-

Strasse 10, HCl G517, 8093 Zürich, Switzerland

${ }^{2}$ Present address: Insplorion AB, Stena Center 1C, 41292 Göteborg, Sweden

${ }^{3}$ Present address: Syngenta, Box 302, 26123 Landskrona, Sweden

*Corresponding author: ted@ifm.liu.se

\begin{abstract}
We report on the preparation and characterization of thin polyampholytic hydrogel gradient films permitting $\mathrm{pH}$-controlled protein resistance via the regulation of surface charges. The hydrogel gradients are composed of cationic poly(2-aminoethyl methacrylate hydrochloride) (PAEMA), and anionic poly(2-carboxyethyl acrylate) (PCEA) layers, which are fabricated by Self-Initiated Photografting and Photopolymerization (SIPGP). Using a two-step UV exposure procedure, a polymer thickness gradient of one component is formed on top of a uniform layer of the oppositely charged polymer. The swelling of the gradient films in water and buffers at different $\mathrm{pH}$ were characterized by imaging spectroscopic ellipsometry. The surface charge distribution and steric interactions with the hydrogel gradients were recorded by direct force measurement with colloidal-probe atomic force microscopy. We demonstrate that formation of a charged polymer thickness gradient on top of a uniform layer of opposite charge can result in a region of charge-neutrality. This charge-neutral region is highly resistant to non-specific adsorption of proteins, and its location along the gradient can be controlled via the $\mathrm{pH}$ of the surrounding buffer. The $\mathrm{pH}$-controlled protein adsorption and desorption was monitored in real-time by imaging surface plasmon resonance, while the corresponding redistribution of surface charge was confirmed by direct force measurements.
\end{abstract}

Keywords: Protein resistance, polyampholytic hydrogel, responsive polymers, thickness gradient, 2-carboxyethyl acrylate, 2-aminoethyl methacrylate.

[ Published in Soft Matter, 10, 5955-5964 (2014). DOI: 10.1039/C4SM00833B. ] 


\section{Introduction}

Hydrogels are hydrophilic, physically or chemically cross-linked polymeric structures, which are particularly attractive for a range of biomedical applications including, for example, drug delivery ${ }^{1}$ and tissue engineering ${ }^{2}$. This interest stems from a combination of useful properties such as antifouling behaviour, tunable mechanical properties, the many routes available for selfassembly, the ease by which biomolecules may be incorporated, and the ability to control swelling or phase transitions by external stimuli, and thereby also diffusion into or out of the polymer network. ${ }^{3}$ These materials are mostly used as bulk materials or in dispersed phases, but also surface-bound hydrogel films are exploited in current research, for cell adhesion, ${ }^{5}$ as ligand matrices in biosensors, ${ }^{6}$ or used for their ability to prevent nonspecific protein adsorption or other types of biofouling. ${ }^{7}$ We are particularly interested in exploiting the antifouling properties of thin hydrogel films, and in the development of tools to achieve and understand these properties.

While high-molecular-weight polyethylene glycol (PEG) brushes are well known to have both excellent resistance to protein adsorption from complex biofluids and very low toxicity in vivo, PEG is also subject to chemical degradation, and is for this reason unsuitable for many long-term or technical applications. Considerable efforts are devoted to finding alternative materials with the antifouling properties of PEG, but with better stability. One of the strategies to achieve this is to attach PEG side-chains to a more stable backbone, and we have demonstrated that PEGbased hydrogel matrices which are graft co-polymerized onto substrates from PEG methacrylate mixtures are suitable for biochip and biosensor applications in demanding biofluids, ${ }^{6}$ and also effectively resist attachment of marine organisms. ${ }^{8}$ Zwitterionic charge-balanced materials have also emerged as interesting alternative candidates for antifouling coatings. ${ }^{9}$ The excellent protein resistance properties of these materials is believed to follow from the lack of a net charge and thus absence of electrostatic interactions with proteins, and the strong hydration due to the high density of charged groups in the polymer, and has been demonstrated in self-assembled monolayers (SAMs), ${ }^{10,11}$ as well as in zwitterionic ${ }^{12,13}$ or amphoteric ${ }^{9,14}$ polymers. In polymers 
this can be accomplished either by inclusion of zwitterionic groups (carboxy- or sulfobetaine, phosphorylcholine etc. $)^{13}$ or by co-polymerizing anionic and cationic monomers. ${ }^{15}$ We have approached this issue in a slightly different way; since these materials are ampholytic, the net charge will depend on the $\mathrm{pH}$, and to investigate $\mathrm{pH}$ effects we have prepared layered polymer gradients, where a homogeneous layer of a charged polymer is covered by a gradient thickness layer of an oppositely charged polymer. The two polymer layers will interpenetrate, and at some thickness of the upper layer, they will form a charge-neutral region. In previous work we have demonstrated that such a hydrogel gradient fabricated from two oppositely charged polymers grafted in sequence, displays a region of high protein resistance. ${ }^{16}$ This region is characterized by charge-balance and reduced swelling due to the absence of charge-charge repulsion, whereas on either side of this charge-balanced region on the gradient there was net surface charge, significant swelling, and protein adsorption was considerable. The use of a gradient surface with continuously varying properties, instead of a polymer bilayer of fixed composition, permits parallel studies of both protein-resistant regions and nearby, less resistant regions of related composition and chemistry. This approach potentially provides better insights into the mechanisms behind the protein resistance. Recently, we demonstrated that the sequentially grafted layers in such two-component gradients are not stratified in the final gradient, but forms a film where the two components are mixed to a great extent. ${ }^{17}$ The swelling of this polymer film is dependent on both the degree of cross-linking in the polymer, as well as the degree of dissociation of ionizable groups. ${ }^{17}$ The latter affects both the hydration and osmotic stress in the polymer, but could also have direct structural effects due to coacervation of oppositely charged groups. For this reason, it is essential that the structure, or swelling, of the polymer film is studied in parallel with the surface charge. If the ionizable groups in the polymers are weak acids or bases, the effective charges in both the bulk of the polymer and at the surface can be controlled by the $\mathrm{pH}$ of the surrounding medium. ${ }^{18-20}$ For these systems, where charge neutralization is related to protein resistance, we hypothesize that the location of the charge-neutral region on the gradients can be controlled with the $\mathrm{pH}$, and also that it should be possible to control the location and extent of protein adsorption via external pH-changes. The preparation of such responsive materiaks is also a topic of great current interest. ${ }^{21,22}$ Early works on responsive hydrogels include 
temperature-sensitive systems based on $\mathrm{N}$-isopropylacrylamide, ${ }^{23}$ and $\mathrm{pH}$-responsive polymers based on methacrylates, ${ }^{24}$ while more recent examples show that volume phase transitions (i.e. mechanical) ${ }^{25-27}$ or wetting ${ }^{28,29}$ properties can be controlled via environmental conditions, such as temperature ${ }^{26}, \mathrm{pH}^{25,27,29}$ or light ${ }^{28}$.

In this work, we followed the variations in surface charge, swelling and protein resistance along thin hydrogel gradients prepared from two oppositely charged layers, as the bulk pH was varied. The gradients were formed from PAEMA, poly(2-aminoethyl methacrylate hydrochloride) and PCEA, poly(2-carboxyethyl acrylate). A P(AEMA-CEA) gradient was formed using a uniform bottom layer of PAEMA and a thickness gradient of PCEA on top. We also made the reverse gradient, P(CEA-AEMA), with PCEA as the uniform bottom layer, covered by a PAEMA thickness gradient. Imaging spectroscopic ellipsometry was used to record the swelling profiles of the hydrogels in various buffers with $\mathrm{pH}$ ranging from 4.3 to 7.5 . The surface charge on the gradients was probed by direct force measurement with colloidal-probe atomic force microscopy (AFM) in the same $\mathrm{pH}$ range, using both negatively charged (carboxylic acid functionalized) and neutral (hydroxyl functionalized) probes. These two probe chemistries were chosen to enable separation of steric interactions with the polymer from the electrostatic contribution. Imaging surface plasmon resonance (iSPR) was used to monitor the adsorption of pepsin and lysozyme, and the response of the adsorption to $\mathrm{pH}$-changes in real-time. Due to the high sensitivity to near-surface refractive index changes in iSPR, changes in the quantity and location of adsorbed proteins can be detected with high accuracy also at very low concentrations. 


\section{Experimental}

Gradient fabrication Gradients for iSPR studies of protein adsorption and force measurements were prepared on $12 \times 12 \mathrm{~mm}^{2}$ gold coated glass SPR substrates (kindly provided by GE Healthcare, Uppsala, Sweden). After TL1-cleaning (in a 5:1:1 mixture of pure water, (Milli-Q, Millipore), $30 \%$ hydrogen peroxide and $25 \%$ ammonia (Merck) for $5 \mathrm{~min}$ at $85^{\circ} \mathrm{C}$ ), SAMs of HSUDA-mPEG ( $\mathrm{HS}\left(\mathrm{CH}_{2}\right)_{11} \mathrm{CONH}\left(\mathrm{C}_{2} \mathrm{H}_{4} \mathrm{O}\right)_{11} \mathrm{CH}_{3}$, PolyPure AS, Norway) were formed in $100 \mu \mathrm{M}$ solutions in $99.5 \%$ ethanol (Kemetyl, Sweden) by incubation for $24 \mathrm{~h}$, followed by 5 min ultrasonication in $95 \%$ ethanol to remove physisorbed molecules before polymerization onto the SAMs. Monomers of CEA (2-carboxyethyl acrylate) and AEMA (2-aminoethyl methacrylate hydrochloride) (Sigma Aldrich) were both diluted in PBS at pH 6.0 for the two-step polymerization process. In this process, the sample surface is suspended beneath a quartz plate through the capillary action of the monomer solution, and irradiated with UV light (Philips TUV PL-L, 18W, main emission peak at $254 \mathrm{~nm}$ ); details of the setup have been published elsewhere. ${ }^{8,16}$ To fabricate a P(AEMA-CEA) gradient, a $15 \%$ (w/v) AEMA monomer solution was UV-irradiated for $5 \mathrm{~min}$ to form a homogeneous bottom layer. The CEA monomer concentration was $1 \%(\mathrm{v} / \mathrm{v})$ and irradiated with 1 min homogeneous pre-illumination followed by 2 min gradient exposure via a moving shutter controlled by a motorized stage at a speed of $0.6 \mathrm{~mm} / \mathrm{min}$, which results in a 1.2 $\mathrm{mm}$ long thickness of PCEA gradient on top of the uniform PAEMA layer. To form a reversed, P(CEA-AEMA) gradient, CEA monomer was irradiated for $3 \mathrm{~min}$, and AEMA monomer was irradiated with 4 min gradient exposure, where the shutter moved at the speed above, but with 10 seconds delay every 50 seconds. This was necessary since the motor driving the shutter could not be made to move slowly enough. Still, due to diffused illumination, this results in a $2 \mathrm{~mm}$ continuous PAEMA gradient on top of the uniform PCEA layer. The surfaces were sonicated in PBS for $1 \mathrm{~min}$ and kept in MQ water at least $12 \mathrm{~h}$ to remove physisorbed polymers and free monomers before use.

For thickness swelling profiles by ellipsometry, silicon substrates with native oxide ( $\mathrm{Si}(100)$, Okmetic, Finland) were used instead of SPR substrates. A silane monolayer was formed by 
incubating the TL1-cleaned surfaces in a mixture of $5 \mathrm{ml} 95 \%$ ethanol, $5 \mathrm{ml} \mathrm{MQ}$ water, $4 \mu \mathrm{l}$ acetic acid and $40 \mu \mathrm{l}$ MPS ( $\gamma$-methacryl oxypropyl trimethoxysilane, PlusOne BindSilane, Amersham Bioscience) for $5 \mathrm{~min}$. The surfaces were then blown dry with nitrogen gas, and baked at $115^{\circ} \mathrm{C}$ for $10 \mathrm{~min}$. To remove unbound molecules, the surfaces were sonicated for 10 seconds and finally stored in $95 \%$ ethanol. The general protocol of gradient fabrication was as above, but the exposure times were adjusted for the fact that polymerization proceeds at different rates on silicon and gold-coated substrates. To form gradients of $P(A E M A-C E A)$, a uniform AEMA layer was prepared by exposure for $4 \mathrm{~min}$, and the CEA gradient was generated by 1 min preillumination and 4 min gradient exposure with delays as above. To form reversed P(CEA-AEMA) gradients, uniform CEA was exposed for $5 \mathrm{~min}$, and an AEMA gradient was generated by 1 min preillumination and $3 \mathrm{~min}$ exposure of the gradient with delays as above. Surfaces were later washed and stored as the SPR surfaces above.

Buffers for $\mathrm{pH}$ control To evaluate the $\mathrm{pH}$-dependent swelling and protein adsorption, the following buffers were prepared: $10 \mathrm{mM}$ acetate buffer (acetic acid, sodium acetate, Sigma Aldrich) was adjusted with $0.1 \mathrm{M} \mathrm{NaOH}$ to pH 4.3; $10 \mathrm{mM}$ MES (2-(N-morpholino)ethanesulfonic acid, Calbiochem) was adjusted with $0.1 \mathrm{M} \mathrm{NaOH}$ to $\mathrm{pH} 5.3$, and $10 \mathrm{mM}$ phosphate buffers (monosodium hydrogen phosphate, potassium dihydrogen phosphate, Sigma) were prepared and adjusted with $1 \mathrm{mM} \mathrm{HCl}$ to $\mathrm{pH} 6.4$ and 7.5.

Protein solutions The protein solutions used for adsorption measurements were pepsin and lysozyme ( $35 \mathrm{kDa}$ and $15 \mathrm{kDa}$, Sigma Aldrich) at a concentration of $0.5 \mathrm{mg} / \mathrm{ml}$ in the buffers above. The studied $\mathrm{pH}$ range falls between the isoelectric points of pepsin (3.2) and lysozyme (9.3), which implies that they remain negatively and positively charged, respectively, over the studied $\mathrm{pH}$ range, therefore the interaction with the charged polymers is assumed to be primarily electrostatic.

Imaging Null Ellipsometry Raw data in the form of $\Delta$ and $\psi$ values over the gradients were collected by an imaging nulling spectroscopic ellipsometer (EP³ $-S E$, Nanofilm, now Accurion, 
Germany) with a flow cell for liquid measurements, at 40 wavelengths between $350-850 \mathrm{~nm}$ at $60^{\circ}$ angle of incidence, using four-zone averaging. The longer measurement time required for a four-zone measurement was rationalized by the elimination of systematic errors arising from, for example, birefringence in the flow cell windows. The imaging window was $0.8 \times 1.2 \mathrm{~mm}^{2}$ and for modeling, the viewed area was divided into 50 ROIs along the gradient. For the measurements in wet state, the buffer was running by a peristaltic pump operating at $0.78 \mathrm{ml} / \mathrm{min}$ into the flow cell with total volume around $3 \mathrm{ml}$. The thickness modeling in air was made by EP3 View software with a three-layer built-in model: $\mathrm{Si} / \mathrm{SiO}_{2} /$ polymer film by Cauchy function. To model the organic film in aqueous solutions, a Bruggeman effective medium approximation was used to account for changes in refractive index upon swelling, while keeping the number of fitting parameters to a minimum. The buffer solutions were assumed to have the same refractive index as water.

Force Measurements by AFM Direct force measurements were performed by a NanoScope IVa Dimension 3100 SPM (Digital Instruments, now Bruker) equipped with a liquid cell which allows in-situ recording in aqueous solutions. Gold-coated glass colloidal probes with $10 \mu \mathrm{m}$ diameter were purchased from NovaScan, these were individually calibrated using the Sader thermal method, with spring constants in the range $0.17-0.2 \mathrm{~N} / \mathrm{m}$. The probes were treated to be negatively charged by the formation of a MUA (11-mercaptoundecanoic acid, Sigma) SAM, or neutral via a 16-thiohexadecanol $\left(\mathrm{C}_{16} \mathrm{OH}\right.$, gift from Biacore) SAM (both SAMs formed via $24 \mathrm{~h}$ incubation in $1 \mathrm{mM}$ solutions in ethanol). We know from previous work on $\mathrm{C}_{16} \mathrm{OH}$ SAMs that charging of these is very small. ${ }^{30}$ In addition, the lack of $\mathrm{pH}$-dependence in the interactions of hydroxylated surfaces (and in particular the difference between hydroxylated and carboxylated surfaces in this regard) has been demonstrated by others. ${ }^{31}$

Force measurements on the hydrogel gradients were made in buffers, and the forces involved in the interaction were normalized with the probe radius and plotted against the separation.

Imaging Surface Plasmon Resonance The protein adsorption profiles were monitored by iSPR, as reported in previous work. ${ }^{16,32}$ Proteins were injected sequentially over the samples, with pepsin followed by lysozyme. For each pH, p-polarized reflectivity spectra were collected after the buffer 
change, after pepsin injection and after lysozyme injection, and s-polarized reflectivity spectra were used as the reference. Injections at a flow rate of $30 \mu \mathrm{l} / \mathrm{min}$ were controlled via a syringe pump. The background buffer was running between protein injections until a stable baseline was attained to remove excess proteins. SPR images were acquired at wavelengths between 600 and $800 \mathrm{~nm}$, together with reflectivity spectra from each individual pixel. The spectra were normalized against the s-polarized spectra to determine the wavelength at which the minimum in reflectance (the SPR wavelength, $\lambda_{S P R}$ ) occurred. The difference of the SPR wavelength $\Delta \lambda_{S P R}$ before and after protein injection quantifies the protein adsorption onto the surface.

\section{Results}

\section{Swelling profiles}

The swelling profiles of $\mathrm{P}(\mathrm{AEMA}-\mathrm{CEA})$ and $\mathrm{P}(\mathrm{CEA}-\mathrm{AEMA})$ gradients are presented as thickness versus position along the gradient in air, water, and in buffers at pH 4.3, 5.3, 6.4 and 7.5 in Figures 1 and 2 . In these figures, the zero position refers to the end exposing the uniform bottom layer, and the gradient thickness increases along the position axis.

Figure 1 shows the $\mathrm{pH}$-dependent swelling of the $\mathrm{P}(\mathrm{AEMA}-\mathrm{CEA})$ gradient. The solid line represents the thickness profile in air, as a dry film, with monotonous increase of polymer content, confirming the presence of a thickness gradient. In water, the whole gradient swells relatively uniformly to approximately twice its dry thickness, and is largely unaffected by $\mathrm{pH}$ changes up to $\mathrm{pH}$ 6.4. With increasing $\mathrm{pH}$, swelling in the PCEA-rich region of the gradient becomes considerable, and the onset of significant swelling also moves towards the thinner region of the gradient. In contrast, swelling in the region of uniform PAEMA thickness on the left side in Figure 1, is relatively constant, with perhaps a small thickness increase for the lowest $\mathrm{pH}$, but otherwise it is not $\mathrm{pH}$-dependent. 

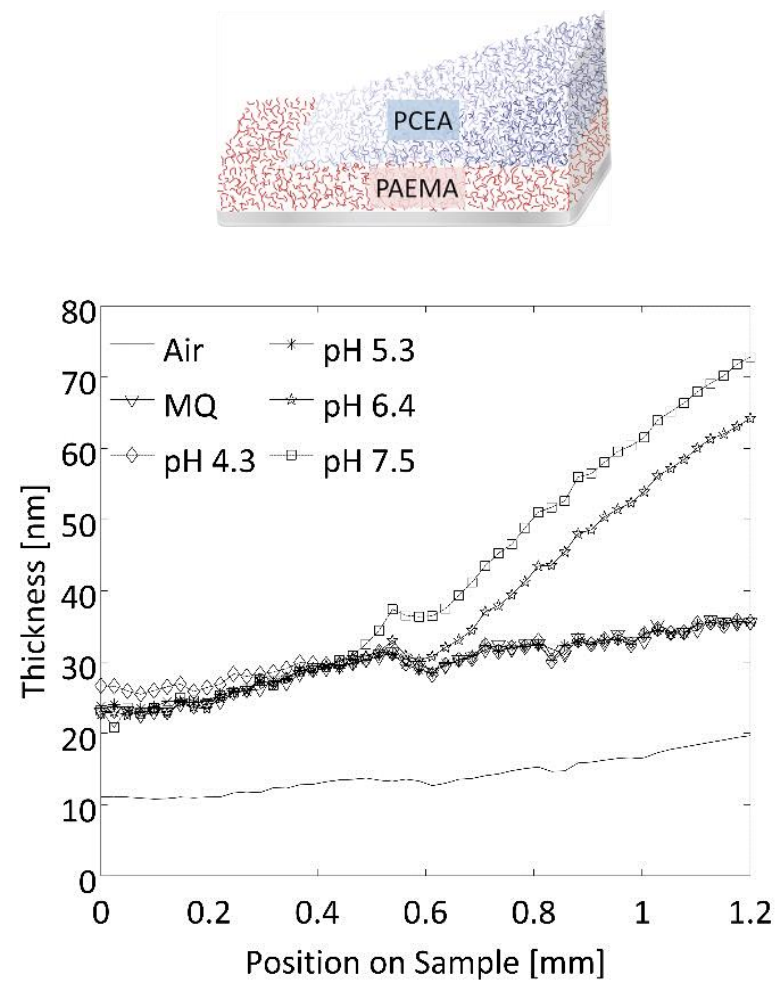

Figure 1. Thickness profile of a $\mathrm{P}(\mathrm{AEMA}-\mathrm{CEA})$ gradient in air, water (MQ), and at various $\mathrm{pH}$ values, as determined by spectroscopic ellipsometry. The thickness of the PCEA gradient increases from left to right, on top of a uniform PAEMA layer, as shown in the cartoon above the diagram.

Figure 2 shows the $\mathrm{pH}$-dependent swelling of a $\mathrm{P}(\mathrm{CEA}-\mathrm{AEMA})$ gradient, where the left region is exposing the uniform bottom layer of PCEA, and the thickness of the PAEMA gradient increases to the right. As was observed in Figure 1, the PAEMA end of the gradient (to the right in Figure 2) is slightly thicker at $\mathrm{pH} 4.3$, but is otherwise insensitive to $\mathrm{pH}$ changes and maintains a constant thickness. Again, the PCEA end is much more sensitive to $\mathrm{pH}$ variations, and swells considerably as the $\mathrm{pH}$ is increased. In contrast to Figure 1, the onset of $\mathrm{pH}$-dependent swelling now moves towards the thicker, PAEMA-rich, end of the gradient with increasing $\mathrm{pH}$. 

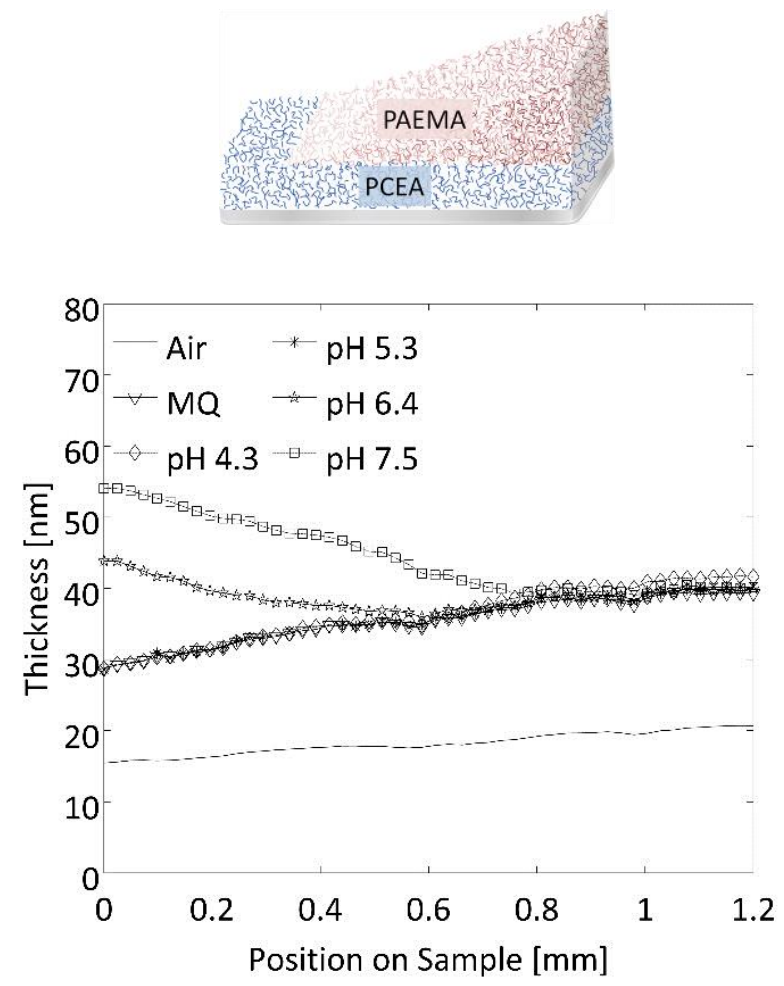

Figure 2. Thickness profile of a $P(C E A-A E M A)$ gradient in air, water (MQ), and at various $\mathrm{pH}$ values, as determined by spectroscopic ellipsometry. PAEMA gradient content increases from left to right, on top of a uniform PCEA layer.

\section{Force measurements}

Figures 3 and 4 show force curves at different positions on the P(AEMA-CEA) and P(CEA-AEMA) gradients in three different $\mathrm{pH}$ buffers. In both figures, the used colloidal probe was modified with a negatively charged MUA SAM, and forces were probed at a series of positions along each gradient at $\mathrm{pH} 5.3,6.4$ and 7.5. At $\mathrm{pH} 4.5$, no repulsion was detected anywhere on the gradients (data not shown). For ease of comparison, the left side of each force curve (the contact, or constant compliance region) indicates the position on the gradient where it was obtained, as shown on the "Actual position" axis. The zero on this axis was (arbitrarily) chosen to coincide with the force curve with the lowest net force (what we later identify as the charge-neutral region) of the gradient at $\mathrm{pH} 6.4$, in both Figures 3 and 4 . 
Figure 3 summarizes the results of force measurements on the P(AEMA-CEA) gradient. Because the probe was negatively charged by the MUA SAM, the interaction is expected to be repulsive against the negatively charged PCEA, and attractive to the oppositely charged PAEMA. For the three $\mathrm{pH}$ values shown, the forces change from long-range attraction at the left, thinner side of the gradient, to long-range repulsion at the right, PCEA-rich side, reflecting a transition from net positive to net negative surface charge. Between these charged regions, there is for every $\mathrm{pH}$ a region where the magnitude of the total interaction is at a minimum (highlighted with red color for each $\mathrm{pH}$ ). It is clear from the data presented in Figure 3 that the location of this minimum shifts with the $\mathrm{pH}$; when $\mathrm{pH}$ is lowered from 6.4 to 5.3, it moves about $300 \mu \mathrm{m}$ towards the thicker end of the gradient, and when $\mathrm{pH}$ is increased from 6.4 to 7.5, this region moves about $400 \mu \mathrm{m}$ toward the thinner end of the gradient instead.

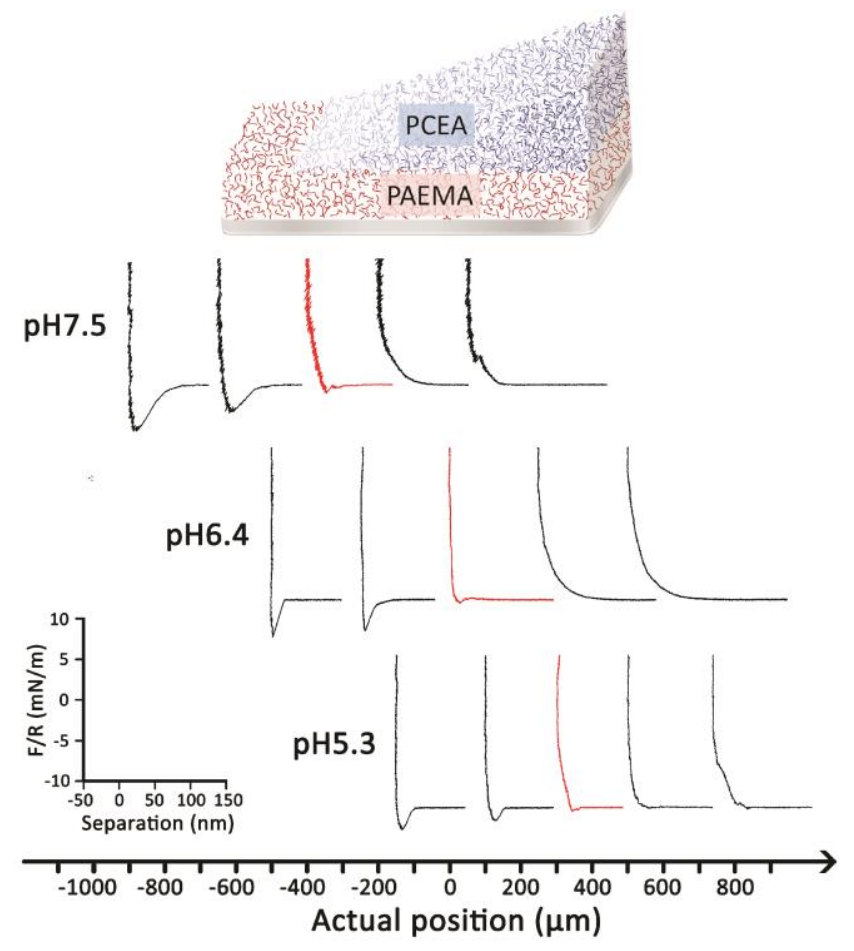

Figure 3. Force curves obtained using an MUA-coated probe on a $\mathrm{P}(\mathrm{AEMA}-\mathrm{CEA})$ gradient, at $\mathrm{pH}$ 5.3, 6.4 and 7.5. The left side of each force curve (the contact region) defines the point on the 
gradient where the force was measured, on the horizontal "Actual position" axis. The inset shows the force and distance scales for the force curves. PCEA gradient content increases to the right along the horizontal axis.

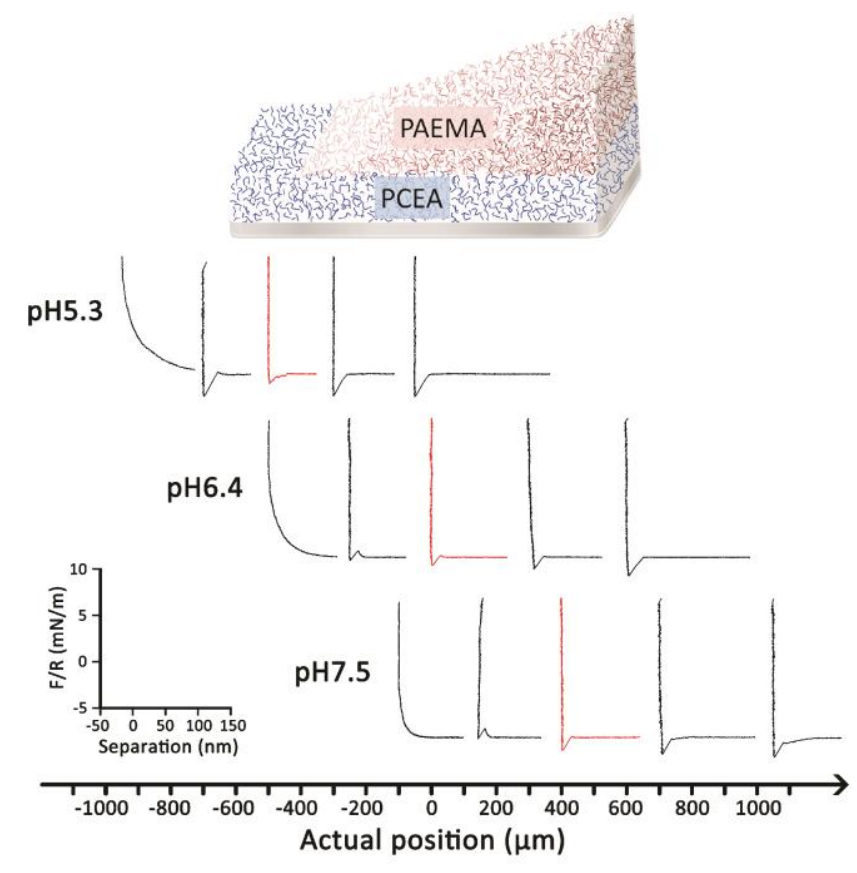

Figure 4. Force curves on the $\mathrm{P}(\mathrm{CEA}-\mathrm{AEMA})$ gradient, at various positions along the gradient, probed at three $\mathrm{pH}$ values. The inset shows the force and distance scales for the force curves. The PAEMA gradient content increases to the right along the Actual position axis.

Figure 4 similarly summarizes the force curves on the P(CEA-AEMA) gradient at three different $\mathrm{pH}$ values, and the data is arranged as in Figure 3. The same kind of features are observed in the set of force curves in Figure 4 as in Figure 3, except that the repulsion observed on the PCEA side is now on the left, thinner, end of the gradient, and the attraction (from PAEMA) on the right. Again, the data confirms that there is a transition from overall repulsive to attractive forces, as we move along the gradient. As in Figure 3, the location of this transition changes with $\mathrm{pH}$, (and for each $\mathrm{pH}$, the curve nearest this region is indicated in red). We note that when $\mathrm{pH}$ is lowered from 6.4 to 5.3 , this position moves about $500 \mu \mathrm{m}$ toward the thinner end of the gradient. In 
contrast, when $\mathrm{pH}$ is increased to 7.5 , this position moves about $400 \mu \mathrm{m}$ to the right, towards the thicker, AEMA-dominated end of the gradient nstead.

In order to clarify the contributions of electrostatic and steric forces to the total interaction, $33-35$ and in particular to investigate the differences between PCEA and PAEMA in this respect, measurements were also conducted on single PCEA and PAEMA layers, without the bottom layer of the oppositely charged polymer, but otherwise identically prepared. Figure 5 is a comparison of the forces obtained on PCEA, probed by a neutral $\mathrm{C}_{16} \mathrm{OH}$ SAM-coated probe (red curve), and those obtained on the P(AEMA-CEA) gradient at $\mathrm{pH} 6.4$ with the MUA probe (black curve). The latter curve is the rightmost force curve in Figure 3 at $\mathrm{pH} 6.4$, and the two samples were matched so that the dry thicknesses of the two polymer films were similar. It is clear that the repulsion on the PCEA surface (red curve) is greater in range than that on the the P(AEMA-CEA) gradient (black curve). The solid blue line in Figure 5 is the expected decay of electrostatic forces in $10 \mathrm{mM}$ electrolyte. The corresponding comparison on the P(CEA-AEMA) gradient is less informative, but is included in the Supplementary Information (Figure S1), for completeness.

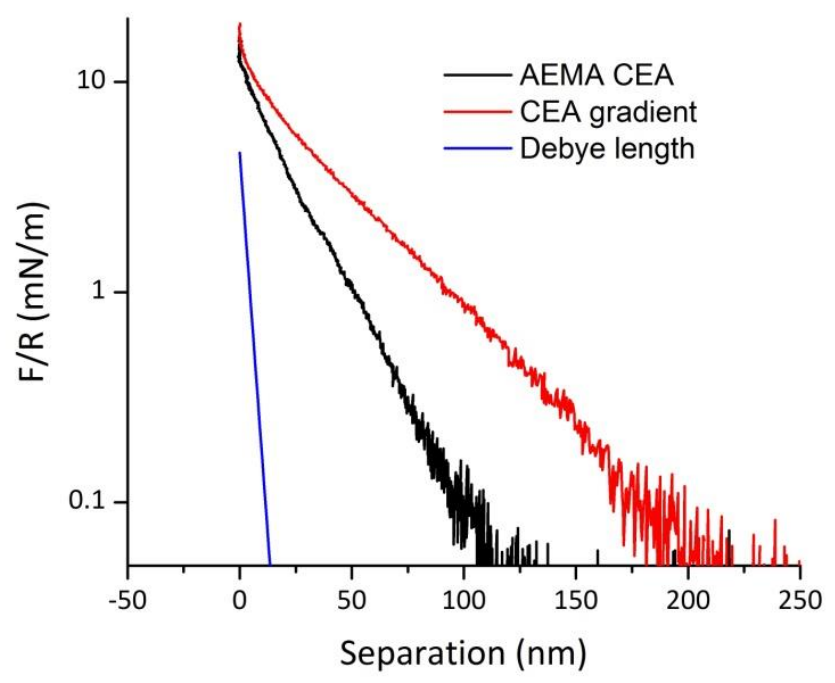

Figure 5. A force curve obtained by interaction of a neutral ( $\mathrm{C}_{16} \mathrm{OH}$ SAM-modified) probe on a PCEA sample (red), together with the total force obtained on the P(AEMA-CEA) gradient (black) 
by a negative MUA probe, where the total polymer thickness is the same in both samples. The blue solid line indicates the expected decay of electrostatic forces with the Debye screening length obtained at $10 \mathrm{mM}$ salt concentration.

\section{Protein adsorption}

The protein adsorption profiles onto both gradients are shown in Figures $6 a$ and 6b, respectively. Pepsin and lysozyme were selected for the experiment since they were expected to adsorb mainly through electrostatic attraction to the oppositely charged sides of the gradients: pepsin to the positive charges of PAEMA and lysozyme should recognize the negative charges of PCEA instead. The protein adsorption on the $\mathrm{P}(\mathrm{AEMA}-\mathrm{CEA})$ gradient was monitored from low to high $\mathrm{pH}: 4.3$ to 7.5 , and on the $\mathrm{P}(\mathrm{CEA}-\mathrm{AEMA})$ gradient by the opposite $\mathrm{pH}$ sequence. The starting (topmost) images of both gradients prior to protein injection were collected to indicate the profiles of the polymer thickness gradients. The amount of adsorbed protein is proportional to the shift in the surface plasmon resonance wavelength $\Delta \lambda_{S P R}$, so in all SPR images after the first protein injection, the wavelength shift recorded from each pixel is plotted versus the position. The details of translating the reflectivity map and spectra can be found in our earlier work. ${ }^{16,32}$ 

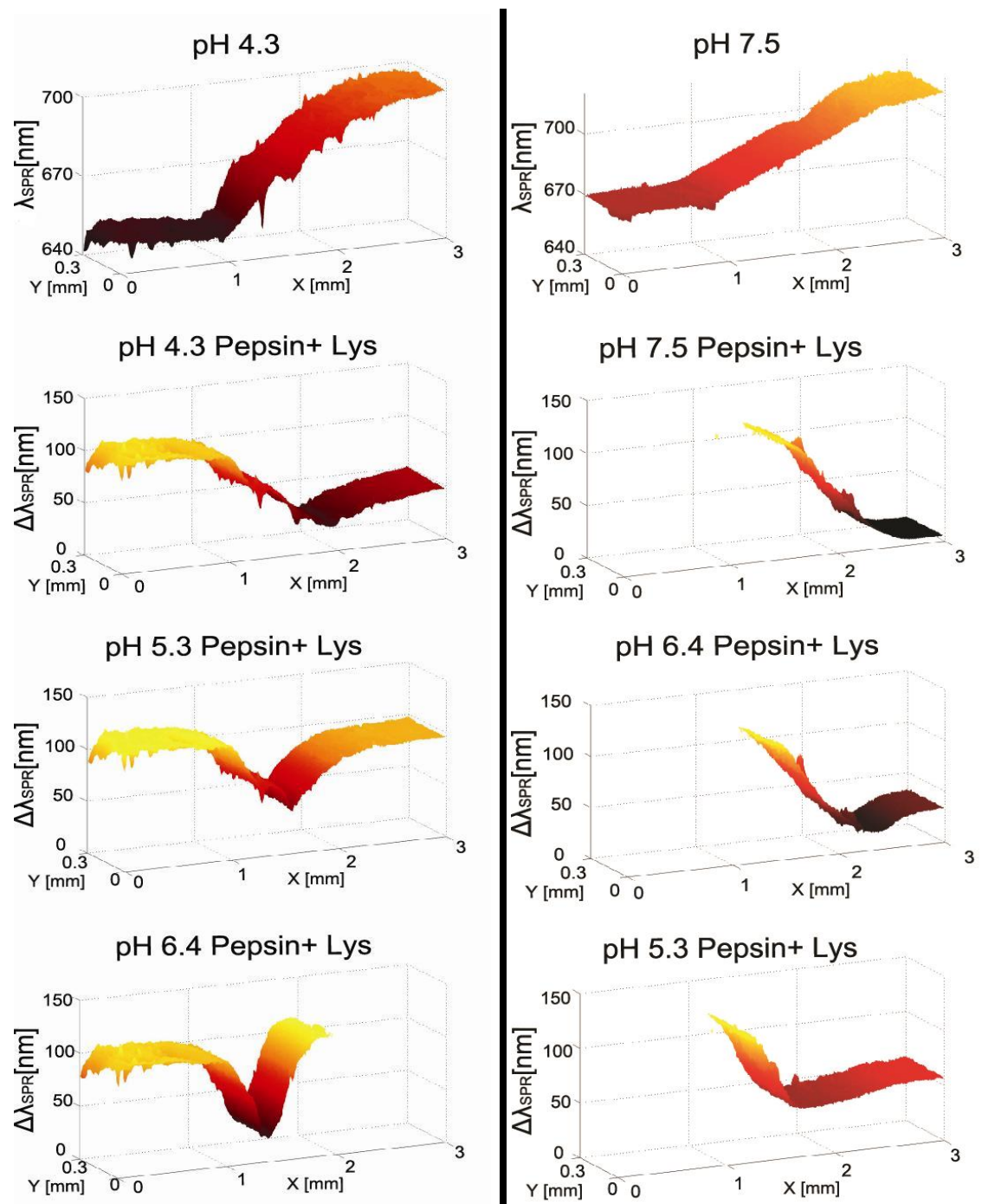

pH 5.3 Pepsin+ Lys

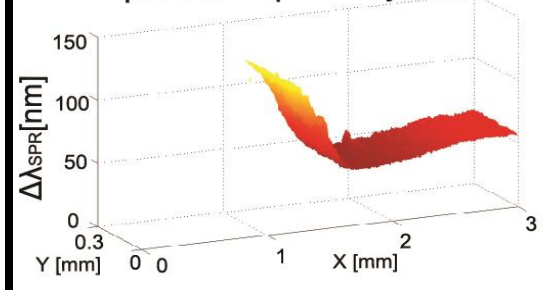

pH 4.3 Pepsin+ Lys
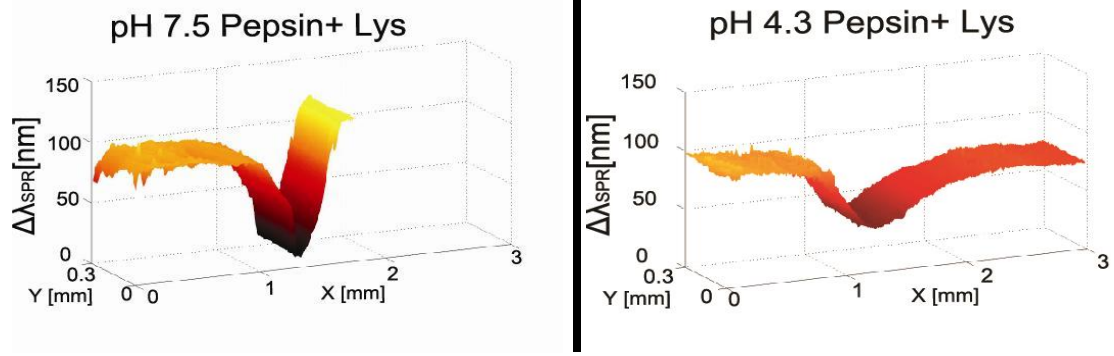
a) $P(A E M A-C E A)$ gradient
b) $P(C E A-A E M A)$ gradient

Figure 6. Protein adsorption profiles on a) the $P(A E M A-C E A)$ gradient, and b) onto the $P(C E A-$ AEMA) gradient. The two top images, $\mathrm{P}(\mathrm{AEMA}-\mathrm{CEA})$ in $\mathrm{pH} 4.5$ and $\mathrm{P}(\mathrm{CEA}-\mathrm{AEMA})$ in $\mathrm{pH} 7.5$, show as the plasmon resonance wavelength $(\lambda)$ versus position (X and $Y$ ) to show the thickness 
gradients before the protein injections. In the following images the shift in SPR wavelength ( $\left.\Delta \lambda_{\text {SPR }}\right)$ is plotted over the gradient surface, to indicate the amount of protein adsorption.

Figure 6a shows the protein adsorption on the $\mathrm{P}(\mathrm{AEMA}-\mathrm{CEA})$ gradient as the $\mathrm{pH}$ is varied from 4.3 to 7.5. Adsorption to the AEMA-rich (left) side of the gradient was relatively high, and also constant for all $\mathrm{pH}$, while adsorption to the CEA-rich (right) end of the gradient was low at low $\mathrm{pH}$, but increasing steadily with $\mathrm{pH}$. Between these regions, there is a region of nearly zero protein adsorption. This region shifts along the gradient towards the thinner end of the PCEA gradient as $\mathrm{pH}$ is increased.

Figure $6 \mathrm{~b}$ shows the protein adsorption on the $\mathrm{P}(\mathrm{CEA}-\mathrm{AEMA})$ gradient from $\mathrm{pH} 7.5$ to 4.3 . Initially, the adsorption onto the CEA-rich (left) side of the gradient is high, while that onto the right, AEMA-rich, end of the gradient is very low. As the $\mathrm{pH}$ is lowered, adsorption to the CEA side decreases gradually, and notably shifts towards the thinner end of the gradient. This is accompanied by a slight increase in adsorption to the AEMA-rich side. Again, there is a region of less adsorption onto the gradient, which changes with the $\mathrm{pH}$, though this minimum is not as distinct as in Figure 6a, but wider and shallower, and the adsorption minima in Figure $6 \mathrm{~b}$ do not have as small adsorption as in $6 a$, where the protein adsorption in the minimum is near zero.

\section{Discussion}

\section{Swelling of the polymer}

The fabrication protocols for $\mathrm{P}(\mathrm{AEMA}-\mathrm{CEA})$ and $\mathrm{P}(\mathrm{CEA}-\mathrm{AEMA})$ gradients were tuned to make the geometries of the two finished gradients as similar as possible, and the asymmetry between CEA and AEMA in the two protocols reflect differences in the polymerization rates of the polymers. The swelling of the polymer films in good solvent is determined by a balance between osmotic stress associated with ionization of fixed charges on the polymer, with subsequent increase in 
counter-ion concentration within the film, and the elasticity of the polymer chains, determined by, among other things, the degree of cross-linking. ${ }^{35-39}$ In Figures 1 and 2, the swelling of the PCEA-rich regions of the gradients are considerably larger than that of the PAEMA regions, and it appears that it is primarily differences in PCEA swelling which move the onset of significant swelling along the gradient as the $\mathrm{pH}$ is varied. This swelling is caused by increasing ionisation of the carboxylic acid groups in the PCEA with increasing $\mathrm{pH}$. In contrast, swelling in the PAEMA regions in Figures 1 and 2 is relatively constant, with perhaps a small thickness increase for the lowest $\mathrm{pH}$, but otherwise not $\mathrm{pH}$-dependent. This is consistent with a swelling at low $\mathrm{pH}$ due to protonation of the amine groups in PAEMA, which are otherwise neutralized at pH above 4.3. This is also confirmed by QCM-D experiments carried out on single-composition films of PCEA and PEAMA (see Supplementary Information).

The dramatic differences in swelling of the two polymers could have several reasons. Clearly, differences in the degree of ionization would be important. In particular, if the $\mathrm{pH}$ is high enough to deprotonate the amines in the PAEMA, the water content may drop dramatically and the amine-functionalized polymer will remain in a collapsed state. ${ }^{24}$ This, however does not seem to be the case, as it is clear from Figure 1 that the PAEMA region in both gradients remains swollen over the whole investigate $\mathrm{pH}$ range, though above $\mathrm{pH} 4.3$ there is very little change in the swelling. The ability of amines to form strong hydrogen bonds also in the deprotonated state is a probable explanation for this behavior. Also structural differences between the polymers could play a role. There is evidence that these SIPGP formed films are cross-linked or branched, ${ }^{6,40}$ but this has not yet been quantified. The two polymers are different in that CEA is easier to polymerize than AEMA, and since the polymerization relies on UV-induced radical formation, there is little control over the structure, which may thus be different for the two polymers. The polymerization in the SIPGP method is a result of hydrogen abstraction from the surface by UVexcited monomers, and the ensuing formation of surface-bound radicals initiate the polymerization. ${ }^{41}$ Thus, it is possible that PAEMA and PCEA have different grafting, branching and/or cross-link densities for equal dry thicknesses of the films, which would result in swelling differences. This is currently a topic of further investigation in our laboratory. 
Despite the observation that swelling of the PAEMA regions is limited at high $\mathrm{pH}$, it is clear that the surfaces of these regions are still positively charged, as is observed from both the attractive force measurements, and also from the adsorption of pepsin onto these regions in the iSPR experiments. Differences in the charging of AEMA moieties between bulk and surface could occur as a result of surface segregation of the polymer, or by differences in the $\mathrm{pK}_{\mathrm{b}}$ between amine groups exposed at the surface, as compared to those buried in the bulk of the polymer.

In agreement with previous work on $\mathrm{P}(\mathrm{MAA}-\mathrm{DMAEMA})^{17}$ and $\mathrm{P}(\mathrm{CEA}-\mathrm{AEMA})^{16}$ gradients, we conclude that the swelling of these ampholytic hydrogel gradients depends strongly on a balance between charge regulation of ions in the polymer, interactions between the two polymers in the thin hydrogel film, as well as on the polymer architecture, such as the degree of cross-linking or branching.

\section{The surface charge of the gradients}

The force measurements show clearly that for each of the three $\mathrm{pH}$ values shown in Figures 3 and 4 , there is a transition between dominating repulsion to dominating attraction, as the probe is moved along the gradient. There are three major contributions to the total interaction; electrostatic forces, steric forces, and van der Waals forces. From the fact that the net interaction changes sign from one end of the gradient to the other, and in an opposite manner on the P(CEAAEMA) and P(AEMA-CEA) gradients, we conclude that electrostatic forces are significant and dominating near the gradient ends. The regions where the magnitude of the total interaction is at a minimum (highlighted with red color for each $\mathrm{pH}$ ), are identified as charge-neutral regions, where electrostatic forces are small, and van der Waals forces and steric contributions from the polymer layer are instead the dominating contributions to the total force. The data in Figures 3 and 4 show that the location of this minimum is $\mathrm{pH}$-sensitive, and thus we are able to control the location of the charge-neutral region on the gradient. The shift of this location from $\mathrm{pH} 5.3$ to 7.5 is approximately $700 \mu \mathrm{m}$ on the $\mathrm{P}(\mathrm{AEMA}-\mathrm{CEA})$ gradient, and ca $900 \mu \mathrm{m}$ on $\mathrm{P}(\mathrm{CEA}-\mathrm{AEMA})$, which is about half the total length of the gradient in both cases. The large shift has positive implications for practical applications, in that the composition resulting in charge neutrality at a particular $\mathrm{pH}$ 
is easily reproduced, and is not dependent on minute differences over a narrow composition range.

The origin of this shift is a combination of a continuous variation in bulk charges of the ionizable groups of the PCEA, and of interactions between the two polymer layers in the gradient. From the swelling results, it seems that volume charging of the AEMA polymer is low in this layer, and apparently negligible in the $\mathrm{pH}$ range included in Figures 3 and 4. A homogeneous variation of the PCEA ionization is in itself not sufficient to explain the moving onset of the $\mathrm{pH}$-dependent swelling. Swelling beyond that which occurs in pure water, starts at some $\mathrm{pH}$ which is determined by the thickness of the gradient. That the location of the minimum moves over a considerable fraction of the gradient length indicates that there is interaction through the surface of the top polymer thickness gradient layer with the underlying homogeneous layer. Thus, it appears that the opposite charges of PCEA and PAEMA cause inner-film-neutralization, which will also reduce swelling. It is interesting to note that there were no signs of such neutralization in the dry state of similar poly(methacrylic acid-dimethyl aminoethyl methacrylate) (P(MAA-DMAEMA)) gradients in a previous study, whose behavior in the hydrated state appears similar to those of the gradients described here. ${ }^{17}$ The interaction of the two polymer layers in the gradient is also confirmed by the comparison of the P(AEMA-CEA) sample with a single PCEA layer in Figure 5. In this graph, it is clear from the indicated decay of electrostatic forces at the used electrolyte concentration, that electrostatic interactions between surface charges on the probe and the polymer, cannot by themselves explain the observed repulsive forces, but that interactions within the mixed polymer films must be considered. The probable cause of the reduced range of force interaction in the P(AEMA-CEA) sample is interaction of PCEA with PAEMA in the two layers which reduces the swelling. This implies that the PCEA and PAEMA layers do not form on top of each other, but that penetration of the monomers from the second polymerization step into the pre-formed bottom layer results in an interpenetrating polymer network, with continuously changing composition, as schematically illustrated in Figure 7, rather than as a second homogeneous layer with continuously changing thickness on top of the first. In the region where the layers interpenetrate, neutralization between the two components occur, and this reduces 
hydration of the functional groups, and hence also the swelling. This picture is in agreement with a preliminary neutron reflectivity study on the interpenetration of neutral polymers, where a deuterium-labeled layer was grown on top of the bottom layer ${ }^{40}$, and a similar study could provide further details of the interpenetration of the polymers also in this work, such as the thickness of the mixed layer, or the monomer density profiles of the two layers.

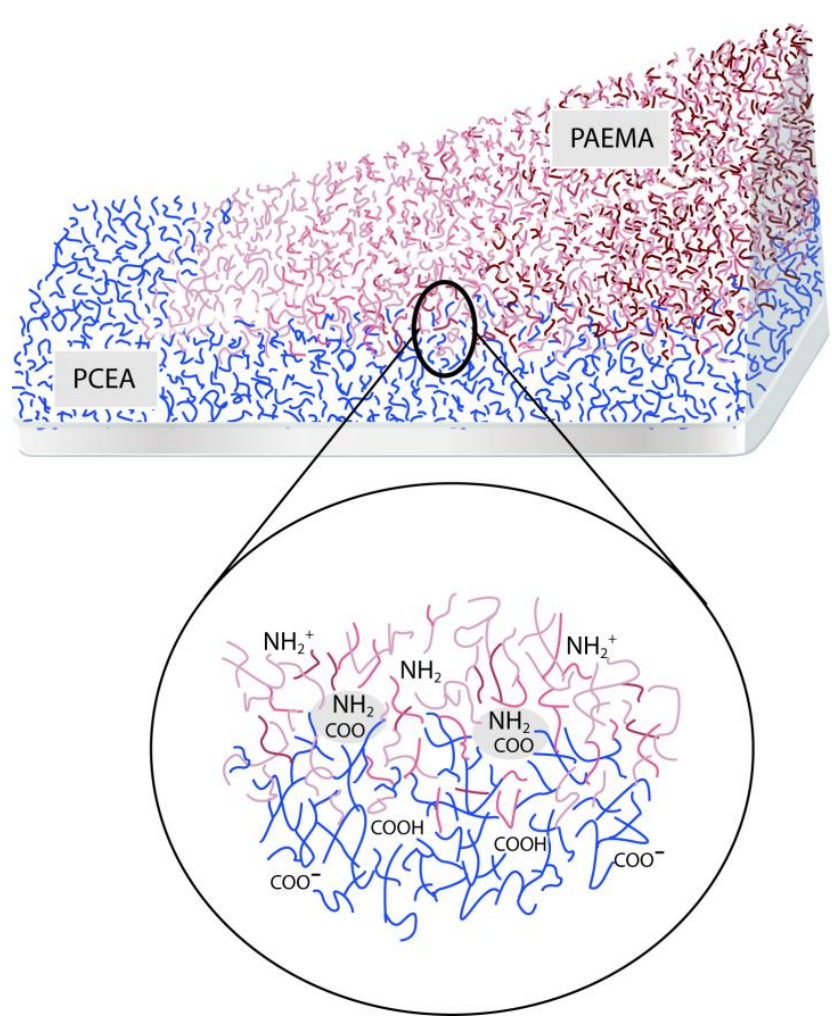

Figure 7. Schematic structure of the interface between the two polymer layers, with a region of interpentrating polymers, where charge neutralization occurs to some degree, while away from the interface, the polymers are charged or uncharged via protonation/deprotonation.

The strong electrostatic attraction to the P(CEA-AEMA) film is in itself of some interest, since it demonstrates that the surface of the PAEMA film is positively charged at pH 6.4 (and according to Figures 3 and 4 also at pH 7.5), even though the swelling behavior in Figures 1 and 2 does not give any clues in this direction. This is also confirmed by the adsorption of pepsin onto the AEMArich regions over most of the $\mathrm{pH}$-range (see further down). This is not unexpected, due to possible 
rearrangement of the polymers near the interface, and due to local differences in $\mathrm{pK}_{\mathrm{b}}$ between the surface and the bulk of the film, as explained above.

We note that the transition from the positively to the negatively charged region in Figure 4 is not as distinct as in Figure 3, but considerably wider. This is in agreement with the results in Figures 1 and 2, where the shift of the onset of swelling is larger in Figure 1, as compared to that in Figure 2. Also, both the repulsive and attractive electrostatic forces, are less pronounced on the P(CEAAEMA) gradient compared to $\mathrm{P}(\mathrm{AEMA}-\mathrm{CEA})$, making the differences between the charge-neutral and the other regions smaller on the P(CEA-AEMA) gradient.

The re-location of the charge-balanced region with $\mathrm{pH}$ in Figures 3 and 4 is consistent with the swelling behavior observed in Figures 1 and 2, but we do not yet have enough data to exactly correlate the location of the charge-balanced region relative to the moving onset of swelling (the different sample requirements for spectroscopic ellipsometry, AFM and iSPR do not permit all experiments to be carried out on a single sample). However, the observations show convincingly that we can control both the swelling and the location of the charge-neutral region by varying the $\mathrm{pH}$. Comparing the swelling of the polymers in response to $\mathrm{pH}$ changes, as observed both by spectroscopic ellipsometry and QCM-D (see Supplementary information), it appears that the pH at which the swelling occurs does not correlate exactly with the change in surface charge, as inferred from the force data in Figure 3 and Figure 4. This might result from a smaller free-energy penalty upon ionization of charges directed towards the ambient buffer, than for ionization of the charges located in the interior of the film. This is supported by thermodynamic models showing that the local variations in $\mathrm{pH}$ across the thickness of thin films of weak polyelectrolytes can be considerable. ${ }^{42}$ Therefore, when investigating the charge of polymer films it is required not to just study the surface charge, but also the degree of ionization in the bulk, which is indirectly seen as swelling, in order to achieve a more complete understanding of the behavior of these polymeric films.

\section{Protein adsorption}


From the sequential adsorption of the two proteins, it is evident that pepsin and lysozyme adsorb to the left and right sides of the gradient in Figure 6, respectively (this is not explicitly shown here, but see Figure 4 in ref ${ }^{16}$ for an example). This indicates the presence of charges of opposite sign on the gradient at $\mathrm{pH} 4.3$, though the amount of adsorbed lysozyme was lower, probably due to the lower degree of ionization of the PCEA, as concluded from both the swelling profiles and the force measurements. At higher $\mathrm{pH}$, there was a gradual loss of pepsin adsorption and a corresponding increase in lysozyme adsorption. This was expected, because the increasing ionization of carboxylic groups on the gradient as the $\mathrm{pH}$ is increased leads to repulsion of pepsin and instead attraction of more lysozyme. Between the areas where pepsin and lysozyme adsorb, there is at every $\mathrm{pH}$ a region of very low adsorption, which shifts via the $\mathrm{pH}$. In conjunction with the data which is presented and discussed above, this confirms previous suggestions that this region is charge-neutral, ${ }^{16}, 38$ and that the protein resistance in this area stems from the elimination of electrostatic interaction, possibly in combination with strong hydration of ionizable groups of the hydrogels.

In Figure $6 \mathrm{~b}$ it is seen that lysozyme adsorbed readily on the PCEA gradient at $\mathrm{pH} 7.5$, but almost no pepsin adsorption is recorded, as would be expected for deprotonated (neutralized) PAEMA at high pH. At $\mathrm{pH} 6.4$, small amounts of pepsin are adsorbed to the PAEMA region, and an adsorption minimum appears. The minimum moves towards the PCEA region as the $\mathrm{pH}$ is decreased, though it is not as distinct as in Figure 6a, and the minimum in Figure $6 \mathrm{~b}$ does not have zero protein adsorption. The low-adsorption region in $6 \mathrm{~b}$ is also wider and shallower compared to $6 a$. This is thought to be due to the structural variations between the two gradients that alter the charge distribution on the surface, though they still keep the dependence on $\mathrm{pH}$. In the P(CEA-AEMA) gradient it thus seems that the positive charges bound to PAEMA are mostly neutralized by the negative charges of the bottom PCEA layer. For this reason, at pH 7.5, pepsin does not adsorb to PAEMA, which is dense and has a low net charge. On the P(AEMA-CEA) gradient, there could be a similar neutralization at $\mathrm{pH} 4.5$ so that the negative probe cannot detect any repulsion from the PCEA part of the gradient. 
However, the observed adsorption is very likely to depend also on both the sequences of $\mathrm{pH}$ variation and protein injection, because the already adsorbed proteins may not immediately desorb when the electrostatic attraction is reduced. ${ }^{16,38}$ Further, in Figure 2, PCEA has a larger pH-dependent swelling compared to PAEMA which results in a dilute negative charge volume, possibly allowing diffusion of lysozyme into the polymer to a greater extent at high $\mathrm{pH}$, which then may prevent desorption as the $\mathrm{pH}$ is decreased. This would be in agreement also with the result that pepsin appears to desorb from the PAEMA region in figure $6 a$, which showed the least degree of swelling. Similarly, according to the profile in Figure 1, PCEA swells significantly, which could result in a larger amount of lysozyme trapped even though the probe cannot detect any negative charges at $\mathrm{pH} 4.5$.

The fact that proteins do desorb between the $\mathrm{pH}$ changes is an indication that the adsorption mechanism of the proteins is primarily electrostatic. It seems, for example, that the proteins remain in a relatively native state, and do not denature upon adsorption, as this would prevent desorption due to exposure of their hydrophobic core to the polymer.

\section{Summary and Conclusions}

In our previous study, ${ }^{16}$ we found that protein adsorption onto a P(AEMA-CEA) gradient is dominated by electrostatic interactions between the surface charge of the hydrogel and the proteins. If the charges of weak polyelectrolytes can be regulated by $\mathrm{pH}$, the lateral distribution of surface charge should have a pH dependence on the ampholytic gradients studied here. The presented data confirms this hypothesis: the net charge of both P(AEMA-CEA) and P(CEA-AEMA) gradients is dependent on the $\mathrm{pH}$, and the location of charge-neutral regions on the gradients can also be controlled by $\mathrm{pH}$. This is further confirmed by the protein adsorption data, where pepsin and lysozyme adsorb selectively to positively and negatively charged regions on the gradients, while the neutral region remains protein-resistant over the tested range of $\mathrm{pHs}$. The quantity of adsorbed protein is inferred from the iSPR images, and is proportional to the surface charge. As the $\mathrm{pH}$ changes, proteins partially or completely desorb in the regions where the $\mathrm{pH}$ - 
change induces a reversal of the surface charge. However, the protein-surface interaction is too complex to be explained solely in terms of electrostatic interactions, which thus cannot completely account for all differences in adsorption between the two gradients.

The ionization of PAEMA and PCEA are both $\mathrm{pH}$-dependent, and neutralization between opposite charges is expected in both gradients. The swelling of PCEA is significantly larger than that of PAEMA. The two primary reasons for this are differences in the degree of ionization in the studied $\mathrm{pH}$ range, and differences in the structure of polymers formed from the two monomers. In practical SIPGP protocols, AEMA monomers are difficult to polymerize compared to CEA monomers, meaning that the protocols for the two reversed gradients are rather asymmetric, and that polymerization conditions need to be very different to prepare structures of similar thicknesses. This has provided insights into how the structure of polymers can affect the protein resistance and also demonstrated how the charge regulation of such a system acts together with structural properties in the control of protein resistance

\section{Acknowledgements}

The authors acknowledge support from the European Commission's 6th Framework Program Integrated Project "AMBIO" (Advanced Nanostructured Surfaces for the Control of Biofouling, NMP-CT-2005-011827) and the European Community's 7th Framework Programme FP7/20072013 under Grant Agreement number 237997 (SEACOAT). T. Ederth acknowledges financial support from the Swedish Government Strategic Research Area in Materials Science on Functional Materials at Linköping University (Faculty Grant SFO-Mat-LiU \# 2009-00971). 


\section{References}

1. Y. Qiu and K. Park, Adv. Drug Delivery Rev., 2012, 64, 49-60.

2. S. Van Vlierberghe, P. Dubruel and E. Schacht, Biomacromolecules, 2011, 12, 1387-1408.

3. J. Kopeček and J. Yang, Polym. Int., 2007, 56, 1078-1098.

4. E. S. Dragan, Chem. Eng. J., 2014, 243, 572-590.

5. S. McRae Page, S. Parelkar, A. Gerasimenko, D. Y. Shin, S. R. Peyton and T. Emrick, J. Mater. Chem. B, 2014, 2, 620-624.

6. A. Larsson, T. Ekblad, O. Andersson and B. Liedberg, Biomacromolecules, 2007, 8, 287-295.

7. Y. Chang, T.-Y. Cheng, Y.-J. Shih, K.-R. Lee and J.-Y. Lai, J. Membr. Sci., 2008, 323, 77-84.

8. T. Ekblad, G. Bergström, T. Ederth, S. L. Conlan, R. Mutton, A. S. Clare, S. Wang, Y. L. Liu, Q. Zhao, F. D'Souza, G. T. Donnelly, P. R. Willemsen, M. E. Pettitt, M. E. Callow, J. A. Callow and B. Liedberg, Biomacromolecules, 2008, 9, 2775-2783.

9. S. F. Chen and S. Y. Jiang, Adv. Mater., 2008, 20, 335-338.

10. S. F. Chen, F. C. Yu, Q. M. Yu, Y. He and S. Y. Jiang, Langmuir, 2006, 22, 8186-8191.

11. R. E. Holmlin, X. X. Chen, R. G. Chapman, S. Takayama and G. M. Whitesides, Langmuir, 2001, 17, 2841-2850.

12. G. Cheng, G. Z. Li, H. Xue, S. F. Chen, J. D. Bryers and S. Y. Jiang, Biomaterials, 2009, 30, 52345240.

13. S. Y. Jiang and Z. Q. Cao, Adv. Mater., 2010, 22, 920-932.

14. M. T. Bernards, G. Cheng, Z. Zhang, S. F. Chen and S. Y. Jiang, Macromolecules, 2008, 41, 42164219.

15. M. E. Schroeder, K. M. Zurick, D. E. McGrath and M. T. Bernards, Biomacromolecules, 2013, 14, 3112-3122.

16. T. Ekblad, O. Andersson, F. I. Tai, T. Ederth and B. Liedberg, Langmuir, 2009, 25, 3755-3762.

17. F. I. Tai, O. Sterner, O. Andersson, T. Ekblad and T. Ederth, Manuscript in preparation.

18. Y. Kamiyama and J. Israelachvili, Macromolecules, 1992, 25, 5081-5088.

19. S. Sanjuan, P. Perrin, N. Pantoustier and Y. Tran, Langmuir, 2007, 23, 5769-5778.

20. N. Schuwer and H. A. Klok, Langmuir, 2011, 27, 4789-4796.

21. D. Kuckling, Colloid Polym. Sci., 2009, 287, 881-891.

22. J. L. Zhang and Y. C. Han, Chem. Soc. Rev., 2010, 39, 676-693.

23. S. Hirotsu, Y. Hirokawa and T. Tanaka, J. Chem. Phys., 1987, 87, 1392-1395.

24. R. A. Siegel and B. A. Firestone, Macromolecules, 1988, 21, 3254-3259.

25. M. S. Jones, Eur. Polym. J., 1999, 35, 795-801.

26. K. A. Melzak, A. Mateescu, J. L. Toca-Herrera and U. Jonas, Langmuir, 2012, 28, 12871-12878.

27. X. Yin, A. S. Hoffman and P. S. Stayton, Biomacromolecules, 2006, 7, 1381-1385.

28. A. A. Brown, O. Azzaroni, L. M. Fidalgo and W. T. S. Huck, Soft Matter, 2009, 5, 2738-2745.

29. A. Mierczynska, A. Michelmore, A. Tripathi, R. V. Goreham, R. Sedev and K. Vasilev, Soft Matter, 2012, 8, 8399-8404.

30. T. Ederth, P. Claesson and B. Liedberg, Langmuir, 1998, 14, 4782-4789.

31. D. V. Vezenov, A. Noy, L. F. Rozsnyai and C. M. Lieber, J. Am. Chem. Soc., 1997, 119, 2006-2015.

32. O. Andersson, A. Larsson, T. Ekblad and B. Liedberg, Biomacromolecules, 2009, 10, 142-148.

33. S. T. Milner, Science, 1991, 251, 905-914.

34. J. N. Israelachvili, Intermolecular and Surface Forces, 2nd edn., Academic Press, 1992.

35. P. M. Biesheuvel, J. Colloid Interface Sci., 2004, 275, 97-106. 
36. S. K. De, N. R. Aluru, B. Johnson, W. C. Crone, D. J. Beebe and J. Moore, J. Microelectromech. Syst., 2002, 11, 544-555.

37. R. Israels, F. A. M. Leermakers, G. J. Fleer and E. B. Zhulina, Macromolecules, 1994, 27, 32493261.

38. O. Sterner, Student thesis, Linköping University, 2010. Available at http://urn.kb.se/resolve?urn=urn:nbn:se:liu:diva-58586.

39. R. Toomey, D. Freidank and J. Ruhe, Macromolecules, 2004, 37, 882-887.

40. T. Ederth and T. Ekblad, Unpublished data.

41. H. L. Wang and H. R. Brown, Macromol. Rapid Commun., 2004, 25, 1095-1099.

42. C. Gong, T. Qi, X. Wei, Y. Qu, Q. Wu, F. Luo and Z. Qian, Curr. Med. Chem., 2013, 20, 79-94. 


\section{Supplementary information}

\section{$\mathrm{pH}$-control of protein resistance of thin hydrogel gradient films}

Feng-I Tai, Olof Sterner ${ }^{1}$, Olof Andersson², Tobias Ekblad ${ }^{3}$ and Thomas Ederth*

Division of Molecular Physics, Department of Physics, Chemistry and Biology, Linköping University, SE-581 83 Linköping, Sweden

${ }^{1}$ Present adress: ETH Zürich, Laboratory for Surface Science and Technology, Wolfgang-PauliStrasse 10, $\mathrm{HCl}$ G517, 8093 Zürich, Switzerland

${ }^{2}$ Present adress: Insplorion AB, Stena Center 1C, 41292 Göteborg, Sweden

${ }^{3}$ Present address: Syngenta, Box 302, 26123 Landskrona, Sweden

\footnotetext{
* Corresponding author: ted@ifm.liu.se
} 


\section{Force measurements}

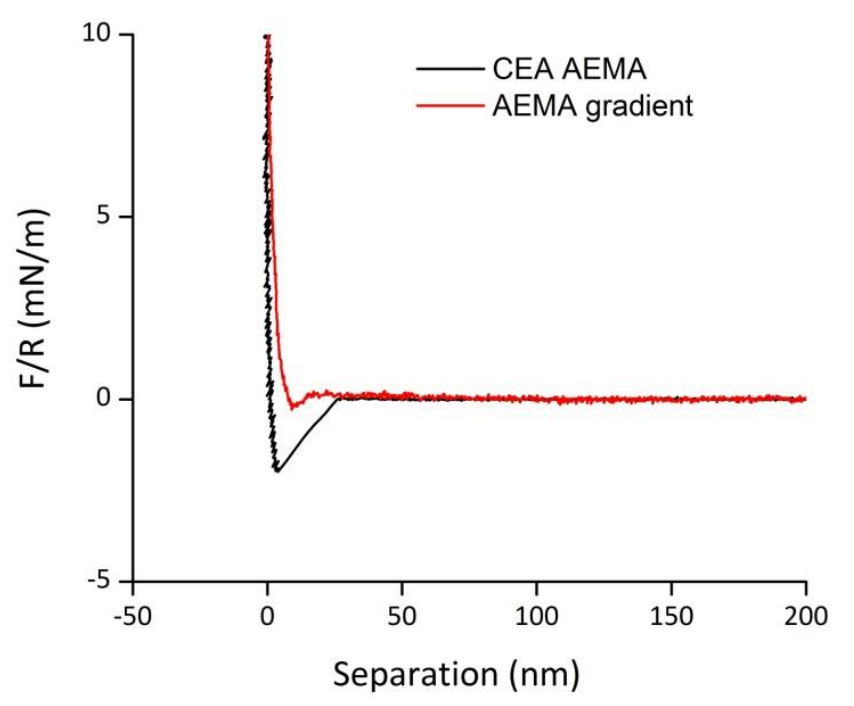

Figure S1. Interaction forces of a neutral $\left(\mathrm{C}_{16} \mathrm{OH}\right.$ SAM-modified) probe interacting with a PAEMA layer (red) plotted together with the interaction measured at the AEMA-dominated end of a the P(CEA-AEMA) gradient (black) with a negative MUA probe. The black curve is the rightmost curve in Figure 4 at $\mathrm{pH} 6.4$ where the attraction is greatest, and the total dry thickness of the polymer layer is the same in both samples. In this case the net force on both surfaces is attractive, but a quantitative comparison of the force curves is difficult, since the van der Waals and attractive electrostatic forces cannot be easily separated due to the fact that the probe "jumps" into contact with the surface when the gradient of the attractive force exceeds the stiffness of the cantilever, leaving very little data in the attractive region for fitting. The electrostatic interaction with the $\mathrm{C}_{16} \mathrm{OH}$ probe is weak due to the low charging of the $\mathrm{C}_{16} \mathrm{OH}$ surface. However, there is a short-ranged but significant steric interaction at about $10 \mathrm{~nm}$ separation in the interaction with the pure PAEMA layer, which is not present in the mixed layer. This indicates a compaction of the mixed film which is not present in the single component, as seen in Figure 5. 


\section{QCM-D data}

Results are shown for PAEMA and PCEA in Figure S2 and Figure S3, respectively. PAEMA showed no mass uptake or change in dissipation at high $\mathrm{pH}(>6)$, and was only marginally swollen at $\mathrm{pH}$ 5.3. At $\mathrm{pH} 4.3$, there was a mass uptake and a positive shift in the dissipation representative of swelling. Interestingly, there response to $\mathrm{pH}$ changes in PAEMA is markedly slower than for PCEA. The reason for this is unclear, but might arise from a different ionisation pattern of the primary amine. The primary amine has high hydrogen bonding capabilities even in its deionised state, which might lower the driving force of the primary amine to be charged, but a complete explanation is, however, difficult to give. PCEA showed an increasing swelling upon raise in $\mathrm{pH}$, with the largest shifts occurring between $\mathrm{MQ}$ and $\mathrm{pH}$ 7.0. This was also expected, as more carboxylic acids became ionised as the $\mathrm{pH}$ was increased. The data correlates well with the ellipsometry data, where the largest swelling response was seen at $\mathrm{pH}$ between 6.1 and 7.0, and only marginally increased swelling between $\mathrm{pH} 7.0$ and 8.0.

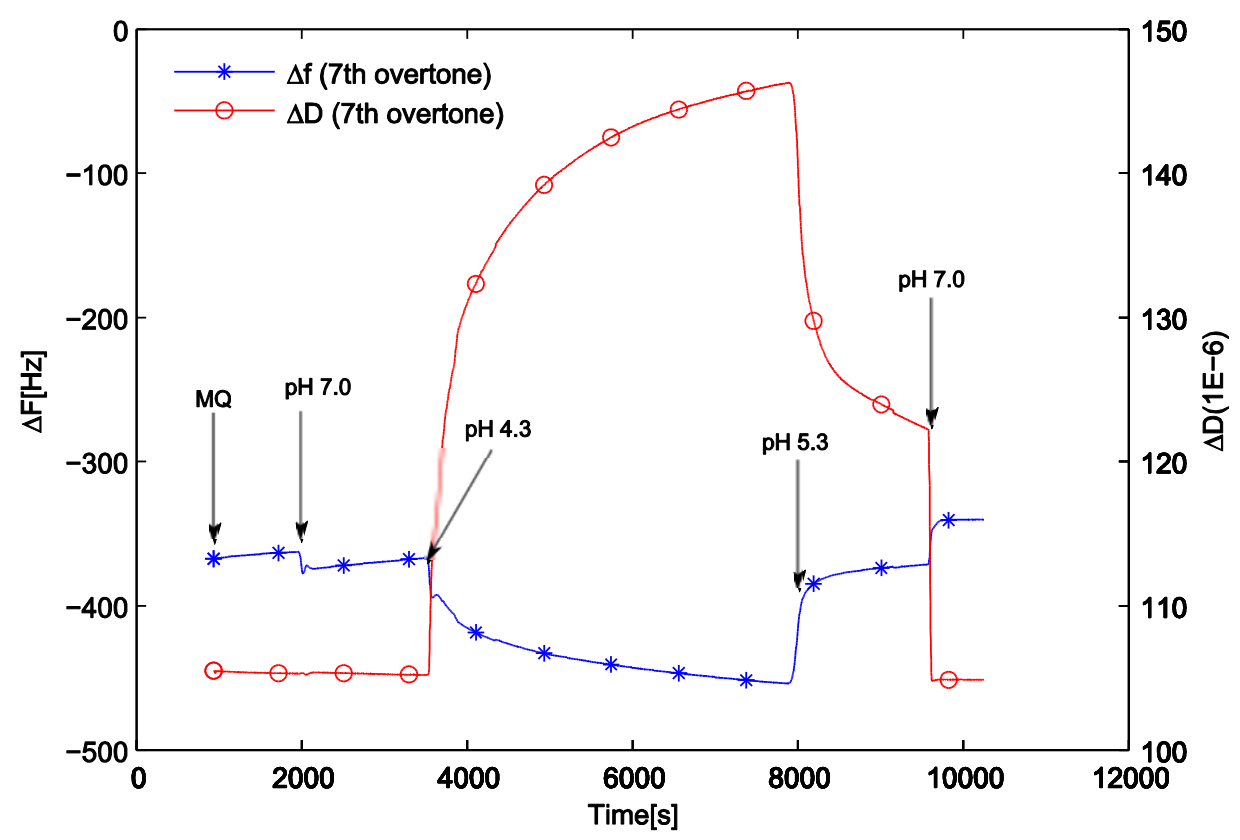

Figure S2. QCM-D data for PAEMA pH-dependent swelling. 


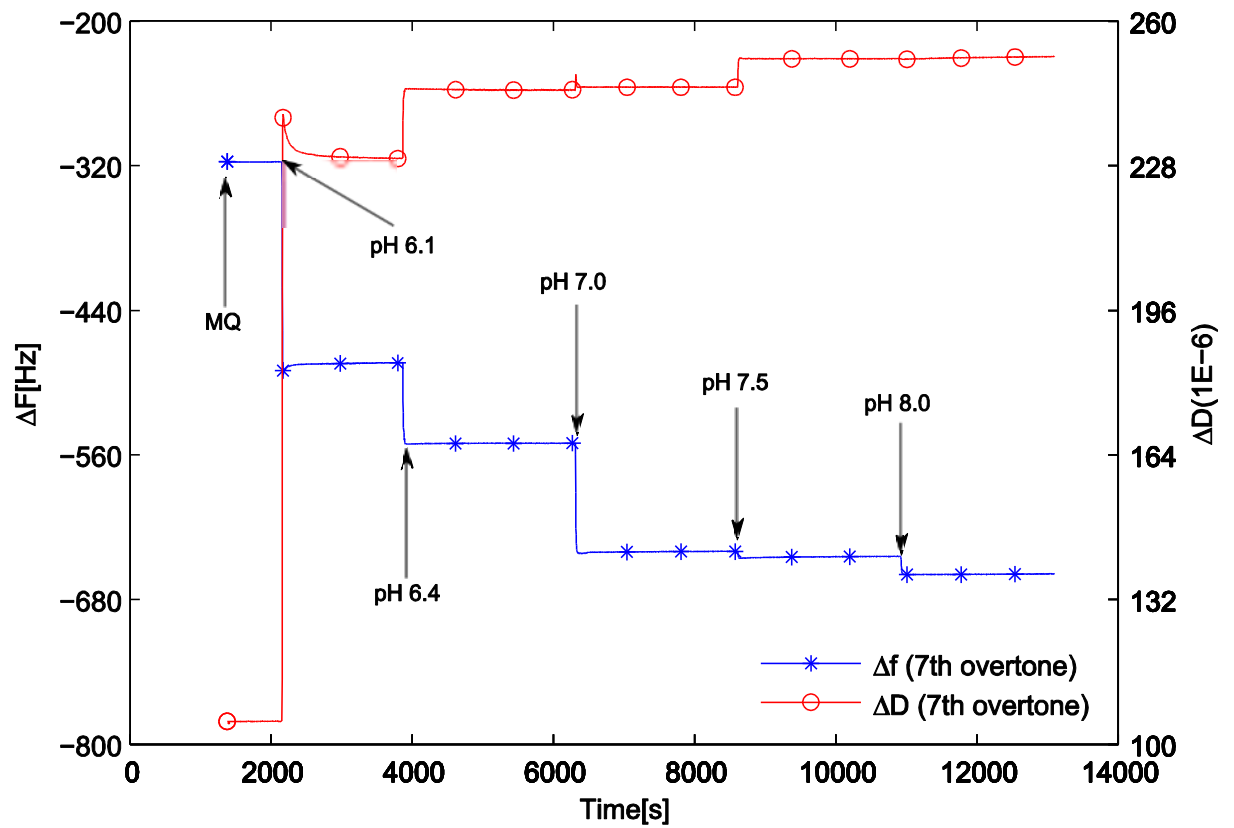

Figure S3. QCM-D data for PCEA pH-dependent swelling. 